\title{
An Investigation of Corrosion Risks in the Oil and Gas Pipelines Using Analytical Hierarchy Process and Fuzzy Analytical Hierarchy Process
}

\author{
Abdulbaset A. Frefer ${ }^{1}$, Mahmoud M. Matoug ${ }^{2}$, Fatma L. Haddada ${ }^{3}$ \\ ${ }^{1,2}$ Mechanical and Industrial Engineering Department, University of Tripoli \\ ${ }^{3}$ Engineering Management Department, University of Tripoli \\ DOI: https://doi.org/10.21467/proceedings.4.49 \\ * Corresponding author email: drfrefer@hotmail.com
}

\begin{abstract}
A B S TRA CT
The products of crude oil and gas can be considered as the main backbone of the global economy. The oil and gas industry has faced many potential risks and problems when the oil and gas is pumped into the pipelines during the production, transportation, and processing. Although experts are solving these problems; some have been difficult to resolve and remained as a complex issue. Among these problems, were the issues of corrosion in the oil and gas pipelines. Risk assessment of the oil and the gas pipelines is considered as the core content of the integrated management of the entire pipelines. This paper aims to assess the risks of corrosion in the oil and gas pipelines in Sabratha platform and Wafaa field. First, the Analytical Hierarchy Process (AHP) is used to identify the risk rate of the different types of corrosion. Second, the technique of Fuzzy Analytic Hierarchy Process (F-AHP) is also used to identify the risk rate of the different types of corrosion. The comparison between the classical (AHP) and the (F-AHP) indicate that the results of both techniques were close.
\end{abstract}

Keywords: Analytical Hierarchy Process (AHP), Fuzzy Analytical Hierarchy Process (F-AHP), Oil and Gas, Pipelines Corrosion, Pipelines Risk Assessment (PRA), Risk Assessment (RA).

\section{Introduction}

There are many reasons for the reduced strength capacity and destruction of pipelines. One of these reasons is the appearance of defects during its manufacture, construction, and operation. According to [1], defects may be visible, hidden, as well as critical, significant and insignificant. Out of all defects of pipeline systems the corrosion defects are considered to be the most significant ones.

Corrosion and other defects in oil and gas pipelines have been serious risks facing operators, inspectors, and corrosion management experts concerned with the offshore/onshore fields; the effects of these risks may be fatal. Oil and gas pipelines risk assessment (PRA) is the core content of the integrated management of the entire pipelines. The PRA allows detecting the danger factors on the pipelines, to facilitate control and prevention of corrosion \& other risks, and to guarantee safe operation of the pipelines [2].

(C) 2018 Copyright held by the author(s). Published by AIJR Publisher in Proceedings of First Conference for Engineering

Sciences and Technology (CEST-2018), September 25-27, 2018, vol. 2 .
This is an open access article under Creative Commons Attribution-NonCommercial 4.0 International (CC BY-NC 4.0)

license, which permits any non-commercial use, distribution, adaptation, and reproduction in any medium, as long as the

AijR original work is properly cited. ISBN: 978-81-936820-6-7 
Research studies have been conducted on various topics to ensure pipeline integrity, reliability, and safety, such as qualitative, semi-quantitative, and quantitative risk assessment techniques [1,3-20]. Examples of these techniques are; the risk assessment matrix, the fuzzy Bayesian Belief network, the Fuzzy Petri net model, Fuzzy logic, AHP, and F-AHP, and the combined Analytical Hierarchy Process - Fault Tree Analysis (AHP-FTA), Monte Carlo, and hazard and operability study (HAZOP). The quantitative and semi-quantitative techniques are considered more accurate and provide more details prioritization of risks than the outcome of qualitative risk assessments techniques that can be evaluated quickly to assess risks.

\section{Statement About the Pipelines Understudy}

This study carried out on five pipelines, which are used in transporting oil and gas at both offshore and onshore fields: namely; (i) 10" condensate, (ii) 16" oil [section A, B, C], (iii) 36" dry gas.

The historical report of the company regarding the detection of these pipelines after pigging (cleaning and inspection) indicates that there are several types of corrosion and other defects in each part of these pipelines, which can be summarized as: (i) Internal Metal Loss, (ii) External Metal Loss, (iii) Gouge Metal Loss, (iv) Dent Metal Loss, (v) Pipe Mill Metal Loss. All types of pipelines defects have been defined and classified in [22] and many more references were cited in [21].

\section{Risk Assessment Techniques Proposed for the Analysis of the Pipelines}

Several techniques have been proposed in order to analyze the risks of the pipelines, identify their causes and limiting their impacts, such as the AHP and the FAHP.

\subsection{The Classical Analytical Hierarchy Process (AHP)}

The theory of AHP is based on the fact that the elements of the problem can be arranged within a separate group, each of which has a specific hierarchical level within the overall hierarchical structure, each level affects directly the above level; therefore, the bottom level is affected too.

\subsubsection{Hierarchical Structuring of the Problem}

The assessment is decomposed into a hierarchy consisted of the problem (goal), then the criteria, followed by sub-criteria and alternatives in lower levels. At the core of the hierarchy is the goal of the problem being studied and analysed. The leaf nodes are the alternatives to be compared.

\subsubsection{Priority Analysis}

The AHP calculates the priorities between the elements of the hierarchy and collecting the opinions, to obtain a set of the overall priorities, and to check the stability of these opinions to draw a final decision based on the results of this process.

Proceedings of First Conference for Engineering Sciences and Technology (CEST-2018), vol. 2 
An Investigation of Corrosion Risks in the Oil and Gas Pipelines Using

Hierarchy Process

\subsubsection{Identification Priorities}

Priority setting is represented by making binary comparisons between elements in the second level of the hierarchy with values ranging from (1 to 9) as shown in Table 1.

Table 1: Saaty' Scale for Quantitative Comparison of Alternatives [5].

\begin{tabular}{|l|l|l|l|l|l|l|l|l|l|}
\hline P.L & E.S & E.T.M.S & M.S & M.T.S.S & S.S & S.T.V.S.S & V.S.S & V.S.T.E.S & E.S \\
\hline N.V & 1 & 2 & 3 & 4 & 5 & 6 & 7 & 8 & 9 \\
\hline
\end{tabular}

Abbreviations in this table mean: P.L=Preference Level, N.V=Numerical Value, E.S=Equally Serious, E.T.M.S= Equally to Moderately Serious, M.S=Moderately Serious, M.T.S.S=Moderately to Strongly Serious, S.S=Strongly Serious, S.T.V.S.S=Strongly to Very Strongly Serious, V.S.S=Very Strongly Serious, V.S.T.E.S=Very Strongly to Extremely Serious, E.S=Extremely Serious.

\subsubsection{Estimating Priorities}

To estimate the priorities in an approximate way; (i) sum of the values in each column should be calculated; (ii) each value should be divided by the summation of the column that allows meaningful comparisons between elements; (iii) the mean of the rows should be calculated by summation of the values in each row and divided by the number of elements in that row [11$13,23]$.

\subsubsection{Consistency Verification}

When the matrix is steady, the normalized summation for each row shows how much each element is dominated by the other relative elements [24-25]. If the rules are contradictory, this value known as (Consistency Ratio), will be greater than 10\% [10,26].

\subsubsection{Estimating the Consistency Ratio}

The consistency ratio is calculated as shown in equation (1) and is required to be less than 0.1 for acceptable consistency [24].

$C R=\frac{C I}{R I}$

\subsection{Where: $\mathbf{C R}=$ Consistency Ratio $\mathbf{R I}=$ Random Index, $\mathbf{C I}=$ Consistency Index}

\subsection{The Fuzzy Analytical Hierarchy Process}

In F-AHP, the factors that affect the decision-making are hierarchically arranged from the overall goal to the criteria, sub-criteria, and alternatives in successive levels.

\section{Triangular Fuzzy Numbers (TFNs)}

Da-Yong [27] has used the extent analysis technique and the principle of (TFN) comparison to obtain the priorities of alternatives from pair-wise comparison. TFNs contain three levels of comparison values; minimum possible value $(\mathrm{L})$, the most possible value $(\mathrm{M})$, and the maximum possible value $(\mathrm{U})$. These values follow the scale shown in Table 2. The technique of F-AHP can be applied by using the equation (2), the fuzzy synthetic extent value (Si) with respect to the (ith) criterion is defined as [14,28]:

$S_{i}=\sum_{j=1}^{m} M_{g i}^{j} \times\left[\sum_{i=1}^{n} \sum_{j=1}^{m} M_{g i}^{j}\right]^{-1}$ 
For $\mathrm{Si}=(\mathrm{Li}, \mathrm{Mi}, \mathrm{Ui})$ and $\mathrm{Sj}=(\mathrm{Lj}, \mathrm{Mj}, \mathrm{Uj})$, the degree of possibility that $\mathrm{Sj} \geq \mathrm{Si}$ for a convex fuzzy number can be obtained from equation (3):

$V\left(S_{j} \geq S_{i}\right)= \begin{cases}1 & \text { if } m_{j} \geq m_{i} \\ 0 & \text { if } l_{i} \geq u_{j} \\ \frac{l_{i}-u_{j}}{\left(m_{j}-u_{j}\right)-\left(m_{i}-l_{i}\right)} & \text { otherwise }\end{cases}$

To obtain estimates for sets of weight values under each criterion, one must consider a principle of comparison for fuzzy numbers, the degree of possibility of $\mathrm{Si} \geq \mathrm{Sj}=(1,2,3 \ldots \mathrm{n})$ should be estimated by using equation (4).

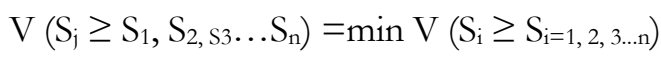

Then, the normalized weight $\mathrm{W}(\mathrm{Si})$ will be formed in terms of a weight vector as follows:

$W=\left(w\left(S_{1}\right), w\left(S_{2}\right), \ldots, w\left(S_{n}\right)\right)^{T}$

Table 2: Linguistic Terms and the Corresponding Triangular Fuzzy Numbers [28].

\begin{tabular}{|l|l|l|l|l|l|l|l|l|l|}
\hline \multicolumn{7}{|c|}{ FAHP } \\
\hline L.S.F.I & E.I & I.1 & M.I & I.2 & I & I.3 & V.I & I.4 & A.I \\
\hline T.F.N & $1,1,1$ & $1,2,3$ & $2,3,4$ & $3,4,5$ & $4,5,6$ & $5,6,7$ & $6,7,8$ & $7,8,9$ & $9,9,9$ \\
\hline T.F.R.N & $1,1,1$ & $1 / 3,1 / 2,1 / 1$ & $1 / 4,1 / 3,1 / 2$ & $1 / 5,1 / 4,1 / 3$ & $1 / 6,1 / 5,1 / 4$ & $1 / 7,1 / 6,1 / 5$ & $1 / 8,1 / 7,1 / 6$ & $1 / 9,1 / 8,1 / 7$ & $1 / 9,1 / 9,1 / 9$ \\
\hline
\end{tabular}

Abbreviations in this table mean: L.S.F.I=Linguistic Scales for Importance, T.F.N=Triangular Fuzzy Numbers, T.F.R.N = Triangular Fuzzy Reciprocal Numbers, E.I=Equally Important, I.1=Intermediate 1, M.I=Moderately Important, I.2=Intermediate 2, I=Important, I.3=Intermediate 3, V.I=Very Important, I.4=Intermediate 4, A.I=Absolutely Important.

\section{Results and Discussion}

The pair-wise comparison for the basic consequences in AHP and F-AHP techniques are done between the three types of consequences listed in Table 3.

Table 3: The Basic Consequences Definitions.

\begin{tabular}{|l|l|}
\hline Consequence Types & Symbol \\
\hline Environmental Impact & EV-I \\
\hline Economic Impacts & EC-I \\
\hline Health-Safety Impacts & HS-I \\
\hline
\end{tabular}

Table 4 clearly shows that the results of both the classical AHP and F-AHP techniques were close enough to agree that health and safety impacts are more important than economic and environmental impacts. The quantitative values explain that the criterion "Health and Safety", would have a higher importance of being attentive than the other two.

Table 4: The Normalized Pair- Wise Comparison Matrix.

\begin{tabular}{|l|l|l|l|}
\hline Criteria & EV-I & EC-I & HS-I \\
\hline AHP & 0.1637 & 0.2972 & 0.5389 \\
\hline F-AHP & 0.0769 & 0.3563 & 0.5667 \\
\hline
\end{tabular}

Proceedings of First Conference for Engineering Sciences and Technology (CEST-2018), vol. 2 826 
An Investigation of Corrosion Risks in the Oil and Gas Pipelines Using

Hierarchy Process

Table 5 shows that the main type of corrosion, which should receive all the attention is the internal metal loss. The obtained result of the F-AHP for (EC-N) has value of zero, which means that the corresponding criterion has no importance as was stated by Liyuan [28].

Table 5: Corrosion Risk Rates of AHP VS. F-AHP for 10" Condensate Pipelines.

\begin{tabular}{|l|l|l|}
\hline & AHP & FAHP \\
\hline IC-N & 0.7851 & 1.0000 \\
\hline EC-N & 0.2148 & 0.0000 \\
\hline
\end{tabular}

Table 6 shows the risk rates of corrosion types for each section in 16" oil pipeline by using both techniques, risk rates in section (A) were very close. The other two types of risks in section (B) are both cancelled in F-AHP, whereas the (IC-B) in AHP is the most important (0.7591). In section C, the classical AHP indicates the (IC-C) is the most important (0.5971), and that the (EC-C) is the next most important (0.2507); whereas the result of F-AHP cancelled both (MD-C) and (DC-C) and left the (IC-C) as the most important, this can be an advantage for F-AHP, where the decision maker can focus on the more important risks as was also reported by Ozdagoglu, et al. [26].

Table 6: Corrosion Risk Rates of AHP VS. F-AHP for 16" Oil Pipelines for Each Section.

\begin{tabular}{|c|c|c|c|c|c|c|c|c|}
\hline \multicolumn{3}{|c|}{ Section A } & \multicolumn{3}{c|}{ Section B } & \multicolumn{3}{c|}{ Section C } \\
\hline & AHP & F-AHP & & AHP & F-AHP & & AHP & F-AHP \\
\hline GC-A & 0.4879 & 0.4809 & GC-B & 0.1132 & 0.0000 & MD-C & 0.0725 & 0.0000 \\
\hline MD-A & 0.5120 & 0.5190 & IC-B & 0.7591 & 1.0000 & IC-C & 0.5971 & 0.8300 \\
\hline & & & DC-B & 0.1276 & 0.00000 & EC-C & 0.2507 & 0.1700 \\
\hline & & & & & & DC-C & 0.0796 & 0.0000 \\
\hline
\end{tabular}

In 36", dry gas pipeline, pair-wise comparison proofed that (MD-D) was less important than the (IC-D) in AHP. Relatively, this type of risk has no importance in F-AHP, but (IC-D) was rated with value of one as the most risky type of corrosion in this study as shown in Table 7.

Table 7: Corrosion Risk Rates of AHP VS. F-AHP for 36" Dry Gas Pipelines.

\begin{tabular}{|l|l|l|}
\hline & AHP & FAHP \\
\hline IC-D & 0.8648 & 1.0000 \\
\hline MD-D & 0.1351 & 0.0000 \\
\hline
\end{tabular}

\section{Conclusions}

The analysis of the risk assessment results as was discussed elsewhere [3,29] indicates that there is a range from convergent to divergent. Results showed that these pipelines are subject to damage due to high-risk rates of some types of corrosion and other defects. In the 10" condensate pipeline and by using the classical AHP, the type of corrosion that should receive all the attention is the (IC-N) (0.7851). However; in the 16" oil pipeline section A, the defect of (MD-A) when using the classical AHP was the most important (0.5120) than the other (GCA). These results were close enough to the results of the F-AHP. In section B, the (IC-B) in the classical AHP was the most important (0.7591) and the other two types of risks were both 
cancelled in F-AHP. In section C, the classical AHP indicates the (IC-C) is the most important (0.5971), and the (EC-C) was the next most important (0.2507); whereas the result of F-AHP cancelled both (MD-C) and (DC-C) and left the (IC-C) as the most important. Decision maker may be able to focus on the most significant types of risks. In oil and gas pipelines, assessment techniques allow corrosion risks to be assessed after the inspection processes (in this study, Pigging was the process used to inspect the five (5) pipelines). This can help the inspectors focus on the types that have high influence on pipelines.

\section{References}

[1] GOST 15467, “Quality Management. Basic Concepts. Terms and Definitions, IPK Izd-vo standartov, Moscow, 2009.

[2] D. Hang, W. Lixin, and W. Qiannan, "A Study on Oil Pipeline Risk Assessment Technique Based on Fuzzy Analytic Hierarchy Process", The Open Petroleum Engineering Journal, pp. 125-129, 2014.

[3] F. Afaf, "Corrosion Risk Assessment Study Onshore Field", M.Sc. Thesis, College of Engineering, University of Tripoli, 2008.

[4] K. Golam, S. Rehan, and T. Solomon, "A Fuzzy Bayesian Belief Network for Safety Assessment of Oil and Gas Pipelines”, Structure and Infrastructure Engineering Journal, vol. 12, no. 8, pp. 874-889, 2016.

[5] Z. Tan, J. Li, Z. Wu, J. Zheng, and W. He, “An Evaluation of Maintenance Strategy Using Risk Based Inspection”, Safety Science, vol. 49, pp. 852-860, 2011.

[6] G. Yanbao, M. Xiaoli, W. Deguo, M. Tao, L. Shuhai, and H. Renyang, "Comprehensive Risk Evaluation of LongDistance Oil and Gas Transportation Pipelines Using a Fuzzy Petri Net Model”, Journal of Natural Gas Science and Engineering, vol. 33, pp. 18-29, 2016.

[7] H. Abid, "Security of Cross-Country Oil and Gas Pipelines: A Risk-Based Model", Journal of Pipeline Systems Engineering and Practice, vol.7, no.3, pp. 1-8, 2016.

[8] S. Oleg and T. Solomon, "Internal Corrosion Hazard Assessment of Oil \& Gas Pipelines Using Bayesian Belief Network Model”, Journal of Loss Prevention in the Process Industries, vol. 40, pp. 479-495, 2016.

[9] Z. Qi, W. Wei, L. Dongpeng, L. Kaikai, and Q. Qiao, "Estimation of Corrosion Failure Likelihood of Oil and Gas Pipeline Based on Fuzzy Logic Approach", Engineering Failure Analysis, vol. 70, pp. 48-55, 2016.

[10] C. Briggs, "Risk Assessment in the Upstream Crude Oil Supply Chain: Leveraging Analytic Hierarchy Process", Ph.D. Dissertation, Transportation and Logistics, College of Graduate and Interdisciplinary Studies, North Dakota State University, April 2010.

[11] R. Izak, "Applying the Analytic Hierarchy Process to Oil Sands Environmental Compliance Risk Management". Ph.D. Dissertation, College of Management and Technology, Walden University, 2014.

[12] B. Abdul-Lateef, M. Abdul-Nasir, and M. Adekunle, "A Fuzzy Multi-Criteria Decision Support System for Evaluating Subsea Oil Pipeline Routing Criteria In East Malaysia”, Environmental Earth Sciences, vol. 74, pp. 4875-4884, 2015.

[13] T. Solomon and S. Rehan, "Risk-Based Environmental Decision-Making Using Fuzzy Analytic Hierarchy Process (FAHP)", Stochastic Environmental Research and Risk Assessment, vol. 21, pp. 35-50, 2006.

[14] K. Dey, "Analytic Hierarchy Process Analyzes Risk of Operating Cross-Country Petroleum Pipelines in India”, Natural Hazards Review, vol. 4, no.4, pp. 213-221, 2003.

[15] B. Yongqiang, L. Lv, and W.Tong, "The Application of the Semi-Quantitative Risk Assessment Method to Urban Natural Gas Pipelines”, Journal of Engineering Science and Technology, pp. 74-77, 2013.

[16] I. Bertuccio and M. Moraleda, "Risk Assessment of Corrosion in Oil and Gas Pipelines Using Fuzzy Logic", Corrosion Engineering, Science and Technology, vol.47, no.7, pp. 553-558, 2012.

[17] D. Prasanta, "Analytic Hierarchy Process Helps Evaluate Project in Indian Oil Pipelines Industry", International Journal of Operations \& Production Management, vol. 24, no. 6, pp. 588-604, 2004.

[18] A. Dawotola, P. van Gelder, and J. Vrijling, "Risk Assessment of Petroleum Pipelines Using A Combined Analytical Hierarchy Process - Fault Tree Analysis (AHP-FTA)”, Proceedings of the Seventh International Probabilistic Workshop, pp. 491-501, 2009. 
An Investigation of Corrosion Risks in the Oil and Gas Pipelines Using ................................... Hierarchy Process

[19] S. Mubin and G. Mubin, "Risk Analysis for Construction and Operation of Gas Pipeline Projects in Pakistan", Pakistan Journal of Engineering \& Applied Sciences, vol. 2, pp. 22-37, 2008.

[20] J. Yadhushree, P. Shiva, and S. Keerthi, "Qualitative Risk Assessment and HAZOP Study of a Glass Manufacturing Industry". International Journal of Advance Research, Ideas and Innovations in Technology, vol. 3, pp. 776-787, 2017.

[21] M. Xie and Z. Tian, "Risk-Based Pipeline Re-Assessment Optimization Considering Corrosion Defects", Sustainable Cities and Society, vol. 38, 746-757, 2018.

[22] J. Roland, T. Susannah, and H. Phil, "Proposal for the Development of an International Recommended Practice in Pipeline Defect Assessment and Repair Selection”, International Conference on the Evaluation and Rehabilitation of Pipelines Prague, pp. 1-27, 2008.

[23] R. Dejan, “A Tool for Risk Assessment”, Safety Engineering, pp.121-122, 2013.

[24] J. Alonso and M. Lamata, "Consistency in the Analytic Hierarchy Process: A New Approach", International Journal of Uncertainty, pp. 445-459, 2006.

[25] M. Ayhan, “A Fuzzy AHP Approach for Supplier Selection Problem.”, International Journal of Managing Value and Supply Chains, pp.11-23, 2013.

[26] A. Ozdagoglu and G. Ozdagoglu, "Comparison of AHP and Fuzzy AHP for the Multicriteria Decision Making Processes with Linguistic Evaluations", Istanbul Ticaret University Fen Bilimleri Dergisi, pp. 65-85, 2007.

[27] C. Da-Yong, "Applications of the Extent Analysis Method on Fuzzy AHP”, European Journal of Operational Research, pp.649-655, 1996.

[28] Z. Liyuan, "Comparison of Classical Analytic Hierarchy Process (AHP) Approach and Fuzzy AHP Approach in Multiple-Criteria Decision Making”, M.Sc. Thesis, University of Nebraska-Lincoln, Nebraska, 2010.

[29] F. Haddada, "Assessment of Corrosion Risks in the Oil and Gas Pipelines in Libya's Onshore/offshore Field", M.Sc. Thesis, College of Engineering, University of Tripoli, 2017.

ISBN: 978-81-936820-6-7 